\title{
An investigation of five component [3+2] self-assembled cage formation using amidinium *-carboxylate hydrogen bonds
}

\author{
Chriso M. Thomas, ${ }^{\dagger}$ Émer M. Foyle ${ }^{\dagger}$ Samuel E. Walker and Nicholas G. White* \\ tThese authors contributed equally to this work \\ Research School of Chemistry, Australian National University, Canberra, ACT, Australia \\ nicholas.white@anu.edu.au,www.nwhitegroup.com
}

\begin{abstract}
The assembly of hydrogen bonded cages using amidinium $\cdots$ carboxylate hydrogen bonding interactions was investigated. A new tris-amidinium hydrogen bond donor tecton based on a tetraphenylmethane scaffold was prepared and its self-assembly with the terephthalate anion studied, and a new tricarboxylate hydrogen bond acceptor tecton was synthesized and its assembly with the 1,3-benzenebis(amidinium) hydrogen bond donor explored. In both cases, molecular modelling indicated that the formation of the cages was geometrically feasible and ${ }^{1} \mathrm{H}$ NMR spectroscopic evidence was consistent with interactions between the components in competitive $\mathrm{d}_{6}$ DMSO solvent mixtures. DOSY NMR spectroscopy of both systems indicated that both components diffuse at the same rate as each other, and diffusion coefficients were consistent with cage formation, and with the formation of assemblies significantly larger than the individual components. An X-ray crystal structure showed that one of the assemblies did not have the desired cage structure in the solid state.
\end{abstract}

\section{Introduction}

Cage and capsule molecules and supramolecular assemblies have received significant research attention, ${ }^{1}$ driven by possible applications in gas storage $^{2}$, stabilisation of reactive species, ${ }^{3}$ and catalysis. ${ }^{4,5}$ Many of these cages are either organic cage molecules held together by covalent bonds, or metal organic cages held together by coordination bonds, however a relatively large number of cages have been assembled using noncovalent interactions such as hydrogen bonding, ${ }^{6-9}$ while a small number have been prepared using halogen or chalcogen bonding. ${ }^{10-13}$

The majority of these hydrogen bonded systems have been prepared from neutral components, and contain relative weak hydrogen bonds. However, some authors have used charge-assisted hydrogen bonds to assemble the supramolecules. Notably, in the early 2000s, CregoCalama showed that a calix[4]arene tetra-amidinium molecule could assemble with a calix[4]arene tetrasulfonate $^{14}$ or tetra-carboxylate ${ }^{15}$ to give two component capsules that were stable in methanol or water. More recently, Szumna has reported a dimeric capsule assembled from two molecules of a resorcinarene appended with four zwitterionic $\mathrm{H}$-bonding groups. ${ }^{16}$

A subtly different approach was pioneered by Furusho and Yashima who used a crescent shaped molecule containing two amidinium motifs and assembled these around poly-carboxylate anions to form five and six component cages. ${ }^{17}$ Very recently, Niemeyer has used a similar approach to form cages based on diphosphonate crescents and poly-amidinium cations. ${ }^{18}$ This kind of multicomponent approach is potentially more versatile, as several different assemblies can be assembled by varying the more easily-synthesized component. Indeed, both Furusho and Yashima, and Niemeyer, have demonstrated this by each preparing two different systems where either the readily-prepared poly-carboxylate (in Furusho and Yashima's case) or poly-amidinium (in Niemeyer's case) was varied. ${ }^{17,18}$

Inspired by the elegant work of Yashima, ${ }^{17,19-21}$ Hosseini ${ }^{22}$ and others, ${ }^{23}$ we have investigated the use of the amidinium $\cdots$ carboxylate interaction in self-assembly. ${ }^{24}$ This interaction can involve two parallel charge-assisted hydrogen bonds $\left[R_{2}^{2}(8)\right.$ in graph set notation, ${ }^{25}$ Figure 1], although we note that other hydrogen bonding arrangements are also commonly observed. ${ }^{26-28}$ These hydrogen bonds can be quite strong and survive in polar solvents or even water: indeed we have reported hydrogen bonded frameworks based on this interaction that can be formed in water, ${ }^{29}$ and can withstand heating in water for extended periods (days). ${ }^{30,31}$

As well as investigating framework formation using the amidinium...carboxylate interaction, we have been investigating whether this interaction can be used to prepare self-assembled cages. Specifically, we envisaged designing a tris-amidinium compound with an appropriate geometry to assemble around dicarboxylate anions such as terephthalate or isophthalate. ${ }^{32}$ Given the wide range of dicarboxylate anions available, we thought that a family of self-assembled cages of varying shapes and sizes could be prepared quite rapidly. In this work, we describe our investigation into the self-assembly of cages assembled through amidinium $\cdots$ carboxylate interactions.

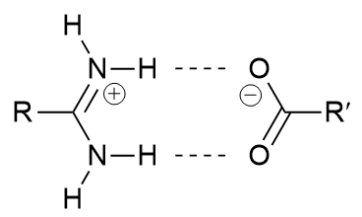

Figure 1 Hydrogen bonding motif used in this work $\left[R_{2}^{2}(8)\right.$ in graph set notation $\left.{ }^{25}\right]$. 


\section{Results and Discussion}

\section{Design of cage systems}

Before attempting to synthesize our cage systems, we used semi-empirical calculations with PM6 parameters ${ }^{33}$ to determine if our proposed systems were geometrically feasible. We initially proposed the tris-amidinium compounds $\mathbf{1}^{3+}$ and $\mathbf{2}^{3+}$ as these appeared relatively easy to synthesize and appeared to have the correct geometry to assemble into cages with terephthalate (TP' ${ }^{2-}$ ) and isophthalate $\left(\mathbf{I P}^{2-}\right)$ anions, respectively. As can be seen in Figure 2, the calculations suggest that the geometries of the components are suitable for cage formation.

\section{Synthesis of tectons}

The tetraphenylmethane based tecton $\mathbf{1}^{3+}$ was synthesised from the known tris-alkyne $3,^{34}$ as shown in Scheme 1.
Sonogashira coupling of $\mathbf{3}$ with 3 -iodobenzonitrile gave tris-nitrile 4; subsequent reaction with lithium bis(trimethylsilyl)amide in THF followed by workup with ethanolic $\mathrm{HCl}$ gave $\mathbf{1} \cdot \mathbf{C l}_{3}$ in good yield. As chloride anions are potentially coordinating and may interfere with the selfassembly process, we exchanged these for noncoordinating $\mathrm{BPh}_{4}{ }^{-}$anions in quantitative yield.

We attempted to prepare $\mathbf{2}^{3+}$ in an analogous manner using a Suzuki coupling of tris-bromomethyl compound 5 35 and 4-cyanophenylboronic acid in conditions similar to those reported by Kotha. ${ }^{36}$ We were able to prepare the new tris-nitrile 6 , albeit in relatively low yield (27\%). However, attempting to convert this to the tris-amidinium $\mathbf{2}^{3+}$ was unsuccessful with a mixture of products being observed: mass spectrometry and NMR spectroscopy indicated that some product was formed but we were not able to isolate this or drive the reaction to completion.<smiles>COc1ccc(C(c2ccc(C#Cc3cccc(C(N)=O)c3)cc2)c2ccc(C#Cc3cccc(C(N)=[NH2+])c3)c(C#Cc3cccc(C(N)=[NH2+])c3)c2)cc1</smiles>

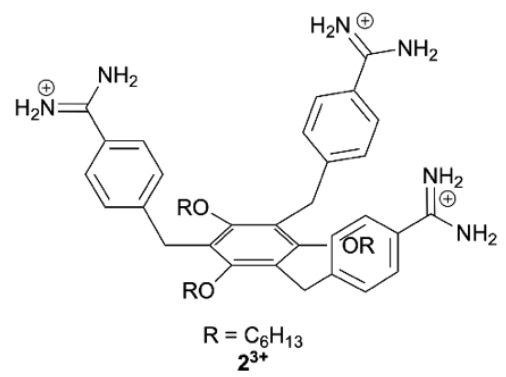<smiles>CC(C)[I+]c1ccc(C(=O)O)cc1</smiles><smiles>CC(C)C(=O)c1cccc(C(=O)[O-])c1</smiles>
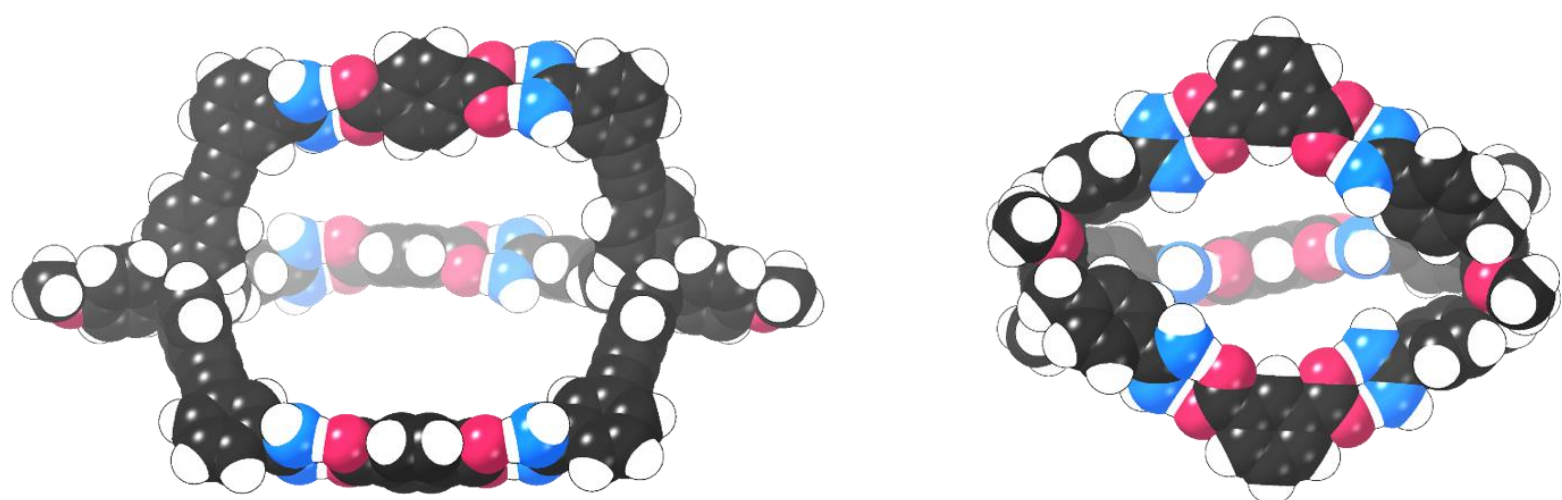

Figure 2 Chemical structures of tectons $\mathbf{1}^{\mathbf{1}^{+}}, \mathbf{2}^{3+}, \mathrm{TP}^{2-}$ and IP2- and optimized gas phase geometries of $\mathbf{1}_{\mathbf{2}} \cdot \mathbf{T P}_{\mathbf{3}}$ and $\mathbf{2}_{2} \cdot \mathbf{I P}_{3}$ calculated using semi-empirical calculations with PM6 parameters..$^{33}$ The hexyl chains of $\mathbf{2}^{3+}$ were replaced with methyl groups for the calculations. 

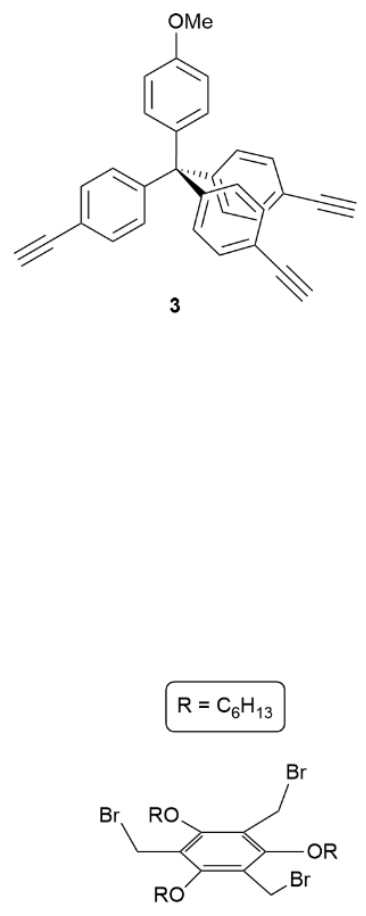

5

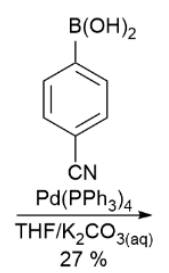

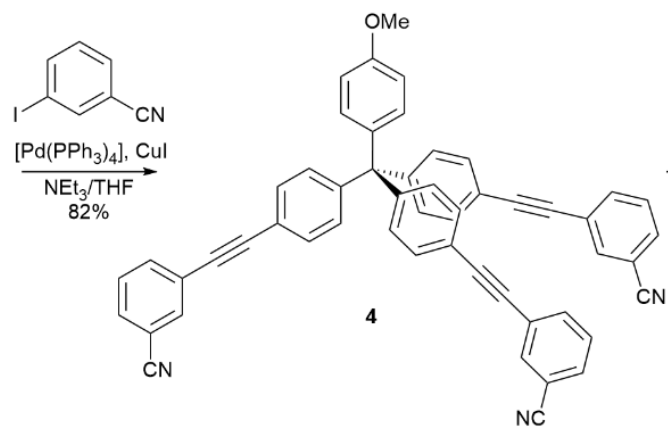

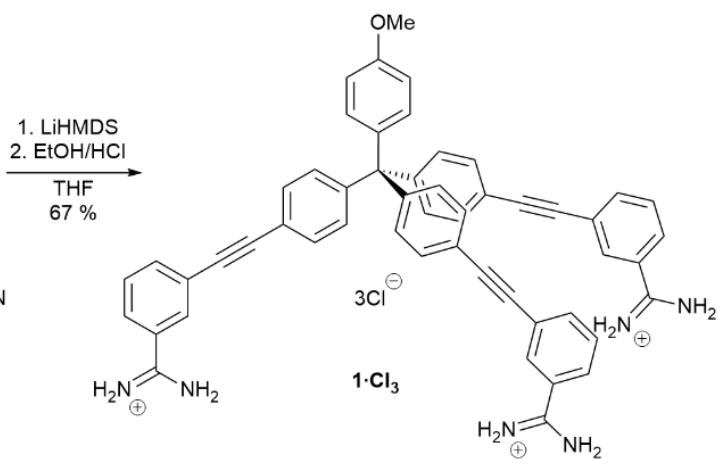

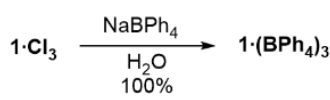

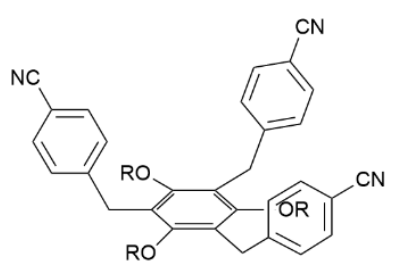

6
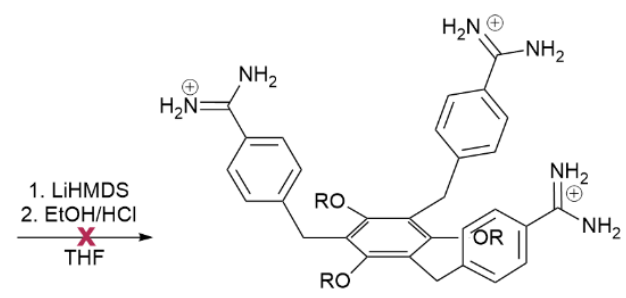

$2^{3+}$

Scheme 1 Synthesis of tris-amidinium $\mathbf{1}^{3+}$ and attempted synthesis of $\mathbf{2}^{3+}$.

Given our inability to synthesize $\mathbf{2}^{3+}$, we next investigated whether it was possible to prepare the tris-carboxylate $7^{3-}$. We reasoned that it would be possible to synthesize a cage from this and the bis-benzamidinium $\mathbf{8}^{2+}$, which would in effect be the "reverse" of the initially-proposed $\mathbf{2 2}_{2} \cdot \mathbf{I P}_{\mathbf{3}}$. Semi-empirical geometry optimizations suggested that this reverse cage, $\mathbf{8}_{3} \cdot \mathbf{7}_{\mathbf{2}}$, was geometrically feasible (Figure S21). The reaction of 5 with 4-methoxycarbonylphenylboronic acid gave the tris-ester 9 in modest yield (26\%), which was subsequently hydrolysed to give the tris-carboxylic acid $7^{3 \mathrm{H}}$ in good yield (81\%). This was then converted to the soluble tetrabutylammonium (TBA) salt, TBA $_{3} \cdot 7$ using TBA.OH (Scheme 2).
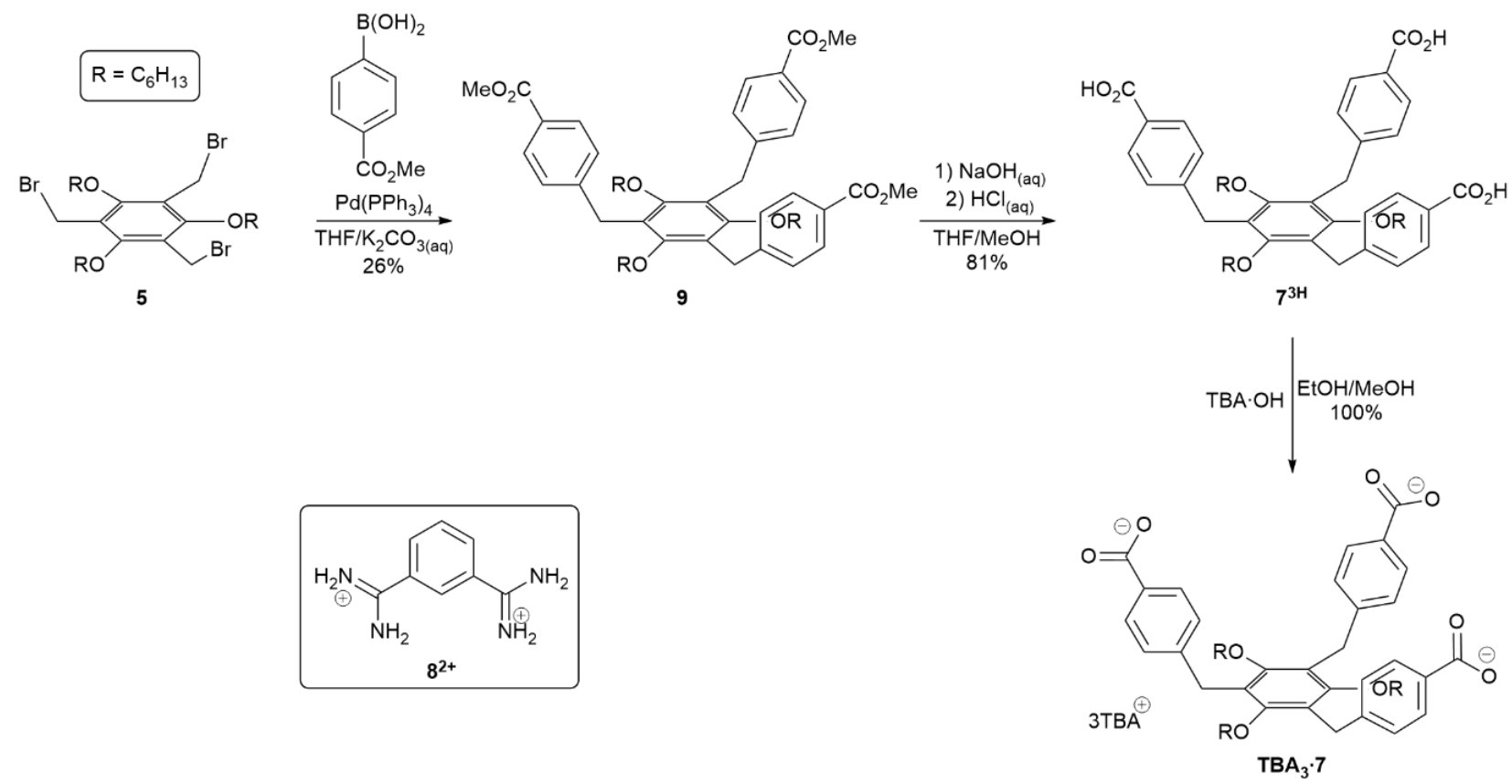

Scheme 2 Synthesis of tricarboxylate $7^{3-}$ and structure of bis-amidinium $\mathbf{8}^{2+}$ 


\section{Investigation of cage formation in solution}

$\mathbf{1}^{3+} /$ TP $^{2-}$ : We initially investigated the formation of cages from $1^{3+}$ and TP $^{2-}$ anions using ${ }^{1} \mathrm{H}$ NMR spectroscopy. Mixing solutions of $\mathbf{1} \cdot\left(\mathbf{B P h}_{4}\right)_{3}$ and TBA $_{2} \cdot \mathbf{T P}$ in $\mathrm{d}_{6}-\mathrm{DMSO}$ resulted in only small shifts $(<0.05 \mathrm{ppm})$ of the resonances of $\mathbf{1}^{3+}$, although significant peak broadening was observed (Figure S15). The small shifts are perhaps not unexpected given the distance between the amidinium/carboxylate groups and the nearest $\mathrm{C}-\mathrm{H}$ proton. Importantly, DOSY NMR spectroscopy shows that $\mathbf{1}^{3+}$ and TP2- diffuse at the same rate, consistent with them forming a supramolecular assembly (Figure 3 and Figure S16). These experiments indicated a diffusion coefficient of $0.75 \times 10^{-10} \mathrm{~m}^{2} \mathrm{~s}^{-1}$, consistent with a species having a solvodynamic radius of $15 \AA$. The calculated structure of $\mathbf{1}_{2} \cdot \mathbf{T P}_{\mathbf{3}}$ (Figure 2 ) is clearly non-spherical, but has approximate dimensions of $40 \times 18$ $\AA$ so a calculated radius of $15 \AA$ (i.e. diameter of $30 \AA$ ) is consistent with cage formation. ${ }^{37}$ Notably, this value is significantly larger that recorded for $1 \cdot\left(\mathbf{B P h}_{4}\right)_{3}$ in the absence of the $\mathbf{T P}^{2-}$ anion [diffusion coefficient for $1 \cdot\left(\mathbf{B P h}_{4}\right)_{3}=1.2 \times 10^{-10} \mathrm{~m}^{2} \mathrm{~s}^{-1}$, solvodynamic radius $=9.5$ $\AA$, Figure S17]. We attempted to grow single crystals to enable us to gain information about the solid state structure of the assembly using X-ray crystallography, but despite numerous attempts we were unable to obtain $\mathrm{X}$-ray quality crystals.

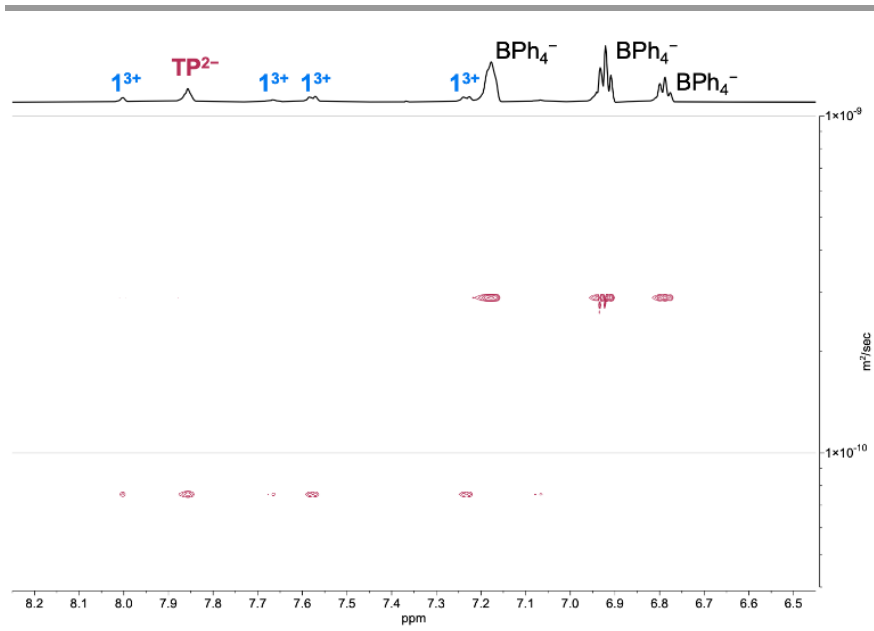

Figure 3 Partial DOSYNMR spectrum of a $2: 3$ mixture of $1 \cdot\left(\mathbf{B P h}_{4}\right)_{3}$ and TBA $_{2} \cdot \mathbf{T P}$ $\left(600 \mathrm{MHz}, 298 \mathrm{~K}, \mathrm{~d}_{6}\right.$-DMSO).

$8^{2+} / 7^{3-}$ : We initially studied cage formation from the tricarboxylate $\mathbf{7}^{3-}$ and bis-amidinium compound $\mathbf{8}^{2+}$ using ${ }^{1} \mathrm{H}$ NMR spectroscopy in $\mathrm{d}_{6}$-DMSO. As shown in Figure 4, significant shifts for the $\mathrm{C}-\mathrm{H}$ peaks of both compounds are observed when solutions of the compounds are mixed. Downfield shifts of $\sim 0.15 \mathrm{ppm}$ are observed for both the peak adjacent to the carboxylate group in $7^{3-}$ and the peak between the amidinium groups in $\mathbf{8}^{2+}$, while smaller upfield shifts are observed for the other amidinium proton resonances. Significant broadening of the resonances corresponding to the amidinium $\mathrm{N}-\mathrm{H}$ groups of $\mathbf{8}^{2+}$ is observed upon mixing with $7^{3-}$ such that these peaks cannot be resolved. DOSY NMR shows that the peaks corresponding to both $\mathbf{8}^{2+}$ and $7^{3-}$ diffuse at the same rate, with a diffusion coefficient of $1.0 \times 10^{-10} \mathrm{~m}^{2} \mathrm{~s}^{-1}$ (Figure $\mathrm{S} 18$ ), corresponding to a solvodynamic radius of $11 \AA$, which is again consistent with cage formation (approximate dimensions: $26 \times 18 \AA$ ). The solvodynamic radius of the mixture of $7^{3-}$ and $\mathbf{8}^{2+}$ is significantly larger than that of $\mathrm{TBA}_{3} .7$ (diffusion coefficient $=1.5 \times 10^{-10} \mathrm{~m}^{2} \mathrm{~s}^{-1}$, solvodynamic radius $=7.4 \AA$, Figure S19).

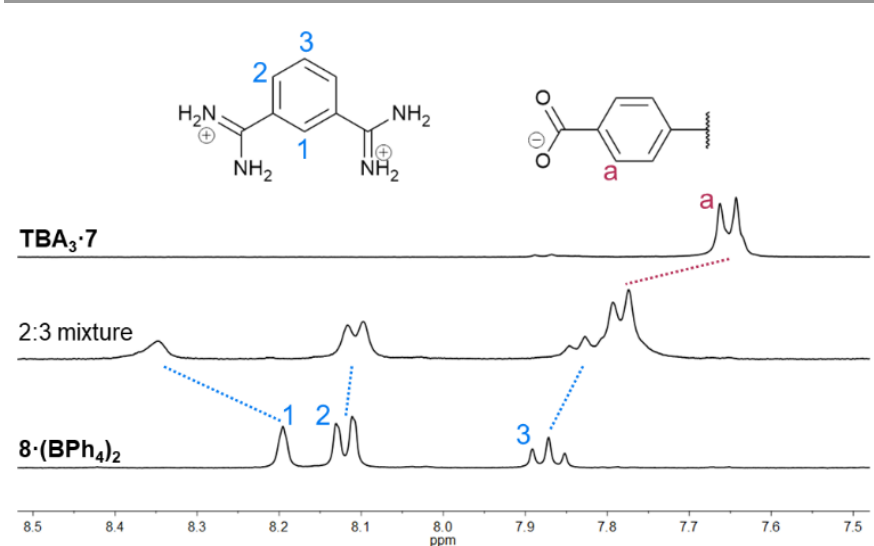

Figure 4 Partial ${ }^{1} \mathrm{H}$ NMR spectrum of $\mathbf{T B A}_{3} \cdot \mathbf{7}, \mathbf{8} \cdot\left(\mathbf{B P h}_{4}\right)_{2}$ and a $2: 3$ mixture of the two; the rest of the aromatic region is not shown as it is dominated by peaks from the $\mathrm{BPh}_{4}^{-}$anions ( $\left.400 \mathrm{MHz}, 298 \mathrm{~K}, \mathrm{~d}_{6}-\mathrm{DMSO}\right)$

\section{Crystal structure of $\mathbf{8 3}_{3} \cdot \mathbf{7 2}_{2}$}

We were able to obtain crystals by diffusing pentane vapour into a DMSO solution containing $\mathrm{TBA}_{3} \cdot 7$ and bisamidinium molecule 8:(BPh4 $)_{2}$. Crystals were small and weakly-diffracting, but with the use of synchrotron radiation it was possible to obtain low quality data and determine the structural connectivity. Despite numerous attempts, it was not possible to resolve the apparently-disordered hexyloxy chains of $7^{3+}$, and so PLATON-SQUEEZE ${ }^{38}$ was used to include these, as well as areas that appear to correspond to disordered solvent molecules, in the model. While detailed inferences about bond lengths/angles are not appropriate given the relatively poor quality of the data, it is clear that in the crystalline state, $\mathbf{8}_{\mathbf{3}} \cdot \mathbf{7}_{\mathbf{2}}$ does not exist as a hydrogen bonded cage (Figure 5). A variety of hydrogen bonding arrangements are seen, including the desired "paired" $R_{2}^{2}(8)$ hydrogen bonding arrangement as well as others. It is notable that of the two molecules of $7^{3-}$ in the asymmetric unit, the expected (and desired) scaffolding ${ }^{39}$ of the 1,3,5-trialkoxybenzene motif has not occurred and this leads to one of the carboxylate groups pointing in the opposite direction to the others, precluding cage formation. We were also able to obtain crystals by diffusing pentane vapour into a DMSO/methanol solution of the compounds; in this case crystals again required synchrotron radiation, but data were of even lower quality. While a stable model 
could not be constructed, the molecular connectivity seems very similar to that shown in Figure 5 (i.e. the crystals appear to be isostructural, but not isomorphous).
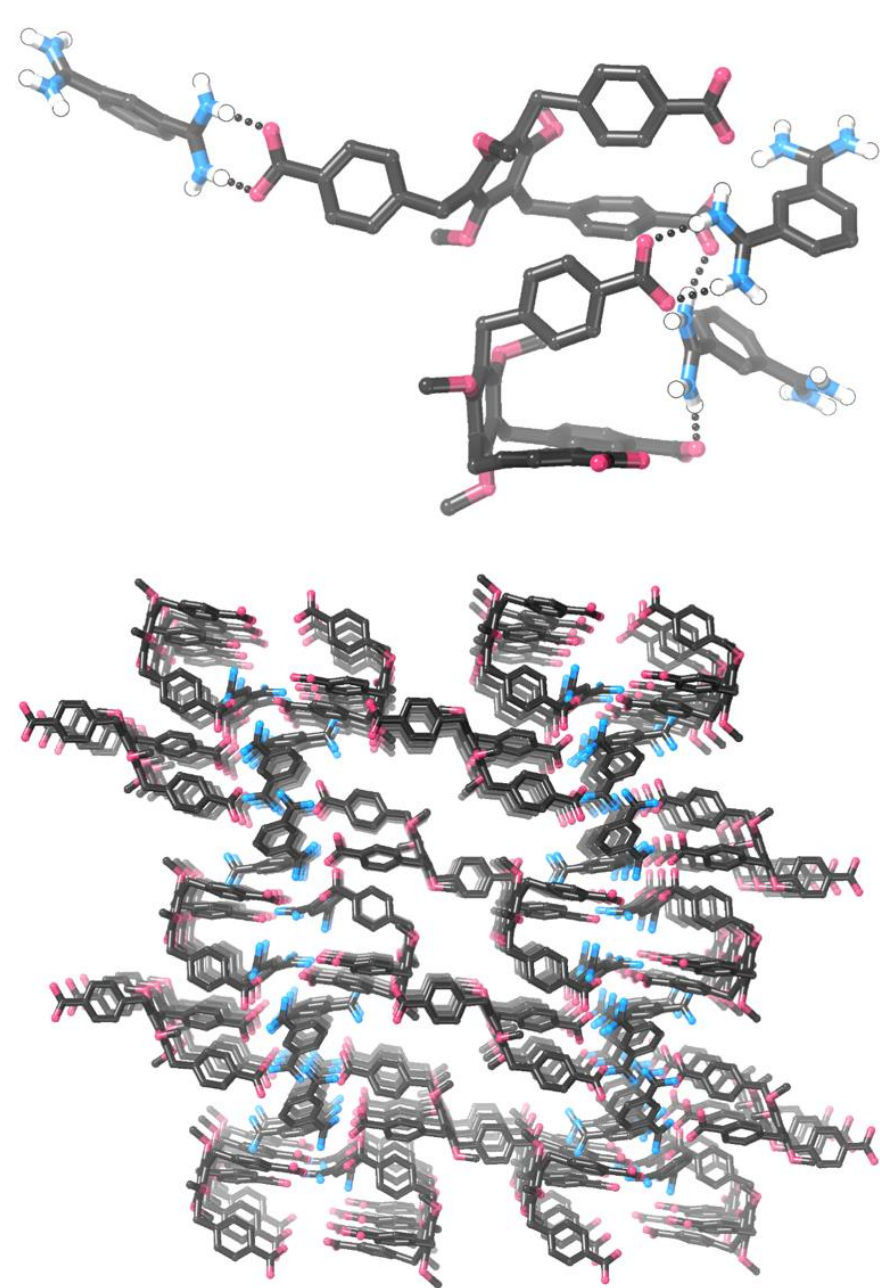

Figure 5 Views of the single crystal structure of $\mathbf{8}_{\mathbf{3}} \cdot \mathbf{7}_{\mathbf{2}}$. Most hydrogen atoms are omitted for clarity, PLATON-SQUEEZE ${ }^{38}$ was used.

\section{Discussion}

DOSY NMR is consistent with formation of the targeted self-assembled cages for both $\mathbf{1}_{\mathbf{2}} \cdot \mathbf{T P}_{\mathbf{3}}$ and $\mathbf{8}_{\mathbf{3}} \cdot \mathbf{7}_{\mathbf{2}}$. While we cannot rule out the formation of small amounts of other species that are in equilibrium with the cages, the observed diffusion coefficients, and the fact that the peaks for both amidinium and carboxylate species diffuse at the same rate are both consistent with cage assembly. It is noteworthy that these cages assemble in the competitive and highly polar solvent $d_{6}$-DMSO. Indeed, we found that the cages showed very poor solubility in all but the most polar solvents. This is in contrast to Furusho and Yashima, ${ }^{17}$ and Niemeyer's ${ }^{18}$ multi-component systems, which were prepared in $\mathrm{CDCl}_{3}$ or $4: 1 \mathrm{CDCl}_{3}: \mathrm{CD}_{3} \mathrm{OD}$, respectively. We note that both of these systems contained $\mathrm{N}$-substituted amidinium groups, where each amidinium nitrogen atom contained one hydrogen atom and one alkyl substituent, where our systems contain no solubilising substituents at the amidinium nitrogen atoms (Figure 6). While there are synthetic challenges associated with introducing alkyl substituents, the ability to use less polar solvents to assemble the cages is clearly advantageous. We designed $7^{3-}$ to include three hexyloxy chains attached to the central benzene ring to aid solubility, but this was clearly not sufficient.
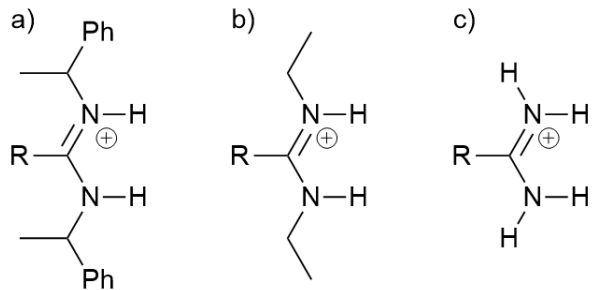

Figure 6 Comparison of the amidinium motifs used to prepare self-assembled hydrogen bonded cages: a) motif used by Furusho and Yashima, ${ }^{17}$ b) motif used by Niemeyer, ${ }^{18} \mathrm{C}$ ) motif used in this work.

X-ray crystallography of single crystals of $\mathbf{8}_{3} \cdot \mathbf{7}_{2}$ did not show the expected cage structure, which we attribute to crystallisation favouring a polymeric structure containing relatively little solvent in preference to a porous cage that would be difficult to pack closely. We note that we have previously attempted to form self-assembled hexagonal macrocycles from simple benzenebis-amidinium and benzenedicarboxylate components, but in that case observed little evidence for hexagon formation. ${ }^{28}$ It is interesting that in this related system we do appear to be able to form relatively well-defined self-assembled structures. We attribute this to the smaller number of components required to self-assemble as well as their higher charge.

\section{Conclusions}

A new tris-amidinium and a new tricarboxylate hydrogen bonding tecton were synthesized and their assembly with an appropriate dicarboxylate or bis-amidinium to form [3+2] self-assembled cages was investigated. While the low solubility of the cages meant we were unable to study this process in solvents other than DMSO, ${ }^{1} \mathrm{H}$ and DOSY NMR spectroscopy data in this solvent were consistent with the formation of the target cages.

\section{Experimental}

\section{General remarks}

The tetraphenyl tris-alkyne $3,{ }^{34}$ the tris(hexyloxy)benzene tris-bromomethyl compound $\mathbf{5}, 35$ bis-amidinium 8-(BPh $)_{2},{ }^{28} \mathbf{T B A}_{2} \cdot \mathbf{T P},{ }^{40}$ and $\mathbf{T B A}_{2} \cdot$ IP $^{28}$ were prepared as previously described. Dry THF was distilled from sodium prior to use, other chemicals were brought from commercial suppliers and used as received. NMR spectra were recorded on Bruker Avance 400 spectrometers and are referenced to the residual solvent signal. ${ }^{41}$ 
Electrospray ionisation mass spectrometry data were acquired on a Micromass Waters ZMD spectrometer.

\section{Tetraphenyl tris-nitrile 4}

A solution of 3 -iodobenzonitrile $(0.18 \mathrm{~g}, 0.77 \mathrm{mmol})$, $\mathrm{Pd}\left(\mathrm{PPh}_{3}\right)_{4}(0.015 \mathrm{~g}, 0.013 \mathrm{mmol})$ and $\mathrm{Cul}(0.0025 \mathrm{~g}, 0.013$ $\mathrm{mmol})$ in triethylamine $(11 \mathrm{~mL})$ was cooled to $0{ }^{\circ} \mathrm{C}$. A solution of the tris-alkyne $3(0.095 \mathrm{~g}, 0.22 \mathrm{mmol})$ in THF (6 $\mathrm{mL}$ ) was added dropwise, and then the reaction was warmed to room temperature and stirred under $\mathrm{N}_{2}$ overnight. The solvent was removed under reduced pressure and the resulting solid was washed with methanol $(10 \mathrm{~mL})$. The remaining residue was dissolved in dichloromethane $(50 \mathrm{~mL})$, washed with water $(30 \mathrm{~mL})$ and dried $\left(\mathrm{MgSO}_{4}\right)$. The solvent was removed under reduced pressure and purified by column chromatography (eluent: $1: 1$ dichloromethane:pet. spirits) to give $\mathbf{4}$ as a yellow powder. Yield: $0.13 \mathrm{~g}(0.18 \mathrm{mmol}, 82 \%)$.

${ }^{1} \mathrm{H}$ NMR (400 MHz, CDCl 3$): 7.79(\mathrm{~s}, 3 \mathrm{H}), 7.72(\mathrm{~d}, J=$ $8.2 \mathrm{~Hz}, 3 \mathrm{H}), 7.61(\mathrm{~d}, J=8.2 \mathrm{~Hz}, 3 \mathrm{H}), 7.44-7.48(\mathrm{~m}, 9 \mathrm{H})$, 7.22 (d, $J=8.0 \mathrm{~Hz}, 6 \mathrm{H}), 7.09$ (d, $J=8.6 \mathrm{~Hz}, 2 \mathrm{H}), 6.83$ (d, $J=8.6 \mathrm{~Hz}, 2 \mathrm{H}), 3.81$ (s, 3H) ppm. ${ }^{13} \mathrm{C} \mathrm{NMR}(101 \mathrm{MHz}$, $\left.\mathrm{CDCl}_{3}\right)$ : 158.0, 147.0, 140.3, 137.7, 137.4, 132.1, 131.2, 131.1, 130.9, 130.0, 125.5, 120.8, 113.3, 93.8, 90.5, 88.1, $64.4,55.4$ ppm (1 peak not detected/overlapping). HRESIMS (pos.) 748.2385, calc. for $\left[\mathrm{C}_{53} \mathrm{H}_{31} \mathrm{~N}_{3} \mathrm{O} \cdot \mathrm{Na}\right]^{+}=748.2365$ $\mathrm{Da}$.

\section{Tetraphenyl tris-amidinium $1 \cdot \mathrm{Cl}_{3}$}

A solution of $4(0.050 \mathrm{~g}, 0.069 \mathrm{mmol})$ in dry THF $(10 \mathrm{~mL})$ was cooled to $-78{ }^{\circ} \mathrm{C}$; under a nitrogen atmosphere a solution of LiHMDS in THF $(1.0 \mathrm{M}, 0.31 \mathrm{~mL}, 0.31 \mathrm{mmol})$ was added dropwise. The reaction mixture was allowed to warm to room temperature and stirred overnight under a nitrogen atmosphere. The resulting golden-yellow solution was cooled to $0{ }^{\circ} \mathrm{C}$ and ethanolic $\mathrm{HCl}$ (prepared by cautiously adding $1 \mathrm{~mL}$ acetyl chloride to $10 \mathrm{~mL}$ ethanol) was added and stirred for 15 minutes. The resulting suspension was taken to dryness under reduced pressure and the solid suspended in water $(10 \mathrm{~mL})$. It was centrifuged for 45 minutes, the supernatant decanted, and the solid thoroughly air-dried to give $\mathbf{1 \cdot} \cdot \mathbf{C l}_{\mathbf{3}}$ as a yellow powder. Yield: $0.040 \mathrm{~g}(0.046 \mathrm{mmol}, 67 \%)$.

${ }^{1} \mathrm{H}$ NMR (400 MHz, d6-DMSO): 9.40 (br. s, $12 \mathrm{H}$ ), 8.00 (s, 3H), 7.84-7.89 (m, 6H), 7.69 (dd, J=7.6, 7.4 Hz, 3H), 7.57 (d, $J=7.8 \mathrm{~Hz}, 6 \mathrm{H}), 7.23(\mathrm{~d}, J=7.8 \mathrm{~Hz}, 6 \mathrm{H}), 7.06$ (d, $J=8.2 \mathrm{~Hz}, 2 \mathrm{H}), 6.94(\mathrm{~d}, J=8.2 \mathrm{~Hz}, 2 \mathrm{H}), 3.75(\mathrm{~s}, 3 \mathrm{H}) \cdot{ }^{13} \mathrm{C}$ NMR (101 MHz, d6-DMSO): 165.6, 158.2, 147.6, 137.5, $136.7,132.1$, 131.8, 131.4, 130.2, 129.6, 129.0, 123.5, $120.3,114.2,91.1,88.8,64.5,55.7$ ppm (1 peak not detected/overlapping). HRESI-MS (pos.): 259.7830, calc. for $\left[\mathrm{C}_{53} \mathrm{H}_{43} \mathrm{~N}_{6} \mathrm{O}\right]^{3+}$, i.e. $1^{3+}=259.7833 \mathrm{Da}$.

\section{Tetraphenyl tris-amidinium 1-(BPh $)_{3}$}

A solution of $\mathrm{NaBPh}_{4}(0.019 \mathrm{~g}, 0.056 \mathrm{mmol})$ in water $(2 \mathrm{~mL})$ was mixed with a suspension of $\mathbf{1 \cdot} \mathbf{C l}_{\mathbf{3}}(0.015 \mathrm{~g}$, $0.016 \mathrm{mmol})$ in water $(3 \mathrm{~mL})$ and the suspension sonicated for 30 minutes. The resulting solid was isolated by filtration, washed wither water $(2 \times 10 \mathrm{~mL})$ and dried in vacuo to give $\mathbf{1 - ( B P h})_{3}$ as a pale orange powder in quantitative yield. Yield: (0.028 g, $0.016 \mathrm{mmol}, 100 \%)$.

${ }^{1} \mathrm{H}$ NMR (400 MHz, d6-DMSO): 9.26 (br. s, $12 \mathrm{H}$ ), 7.97 (s, 3H), $7.88(\mathrm{~d}, J=7.8 \mathrm{~Hz}, 3 \mathrm{H}), 7.83(\mathrm{~d}, J=7.9 \mathrm{~Hz}, 3 \mathrm{H})$, 7.67 (dd, $J=7.9,7.8 \mathrm{~Hz}, 3 \mathrm{H}), 7.57(\mathrm{~d}, J=8.0 \mathrm{~Hz}, 6 \mathrm{H})$, $7.23(\mathrm{~d}, J=8.0 \mathrm{~Hz}, 6 \mathrm{H}), 7.17$ (br. s, $12 \mathrm{H}), 7.06$ (d, $J=8.5$ $\mathrm{Hz}, 2 \mathrm{H}), 6.89-6.94(\mathrm{~m}, 14 \mathrm{H}), 6.79$ (dd, $J=7.2,7.2 \mathrm{~Hz}, 6$ $\mathrm{H}), 3.75(\mathrm{~s}, 3 \mathrm{H}) .{ }^{13} \mathrm{C}$ NMR (101 MHz, d6-DMSO): 165.3, 163.1-164.6 (m), 158.0, 147.4, 137.3, 136.6, 136.0, 131.9, $131.6,131.2,130.1,129.6,128.8,125.8,123.3,122.0$, $120.1,114.0,90.0,88.6,64.4,55.6$ ppm. ESI-MS (pos.): 259.7, calc. for $\left[\mathrm{C}_{53} \mathrm{H}_{43} \mathrm{~N}_{6} \mathrm{O}\right]^{3+}$, i.e. $1^{3+}=259.8 \mathrm{Da}$.

\section{Tris(hexyloxy)benzene tris-nitrile 6}

To a solution of $5(0.400 \mathrm{~g}, 0.608 \mathrm{mmol}, 1$ equiv) in THF $(70 \mathrm{~mL})$ was added 4-cyanophenylboronic acid $(0.352 \mathrm{~g}$, $2.40 \mathrm{mmol}$, 3.91 equiv) and $\mathrm{K}_{2} \mathrm{CO}_{3(\mathrm{aq})}(2.0 \mathrm{M}, 9.4 \mathrm{~mL})$, and the resultant pale yellow solution was deoxygenated with bubbling $\mathrm{N}_{2}$ for 20 minutes. After this time, $\mathrm{Pd}\left(\mathrm{PPh}_{3}\right)_{4}$ ( $0.103 \mathrm{~g}, 0.094 \mathrm{mmol}, 0.154$ equiv) was added and the solution was heated to $75^{\circ} \mathrm{C}$ for 48 hours under $\mathrm{N}_{2}$, during which time the solution turned black. After this, the solution was cooled to room temperature and water $(100 \mathrm{~mL})$ was added. This was then extracted with ethyl acetate $(3 \times 100$ $\mathrm{mL})$, and the resultant organic layer was washed with water $(100 \mathrm{~mL})$ and brine $(100 \mathrm{~mL})$, and then dried $\left(\mathrm{MgSO}_{4}\right)$. The solution was then concentrated under vacuum to leave the crude product as a black oily residue, which was purified via column chromatography (4:1 pet. spirits: EtOAc) to give the product as a colourless oil. Yield 0.119 $\mathrm{g}(0.164 \mathrm{mmol}, 27 \%)$.

${ }^{1} \mathrm{H}$ NMR $\left(400 \mathrm{MHz}, \mathrm{CDCl}_{3}\right): 7.53(\mathrm{~d}, J=8.3 \mathrm{~Hz}, 6 \mathrm{H})$, $7.23(\mathrm{~d}, J=8.3 \mathrm{~Hz}, 6 \mathrm{H}), 4.04(\mathrm{~s}, 6 \mathrm{H}), 3.52(\mathrm{t}, J=6.6 \mathrm{~Hz}$, $6 \mathrm{H}), 1.54-1.58(\mathrm{~m}, 6 \mathrm{H}), 1.18-1.24(\mathrm{~m}, 18 \mathrm{H}), 0.83(\mathrm{t}, J=$ $6.9 \mathrm{~Hz}, 9 \mathrm{H})$ ppm. ${ }^{13} \mathrm{C} \mathrm{NMR}\left(101 \mathrm{MHz}, \mathrm{CDCl}_{3}\right): 156.9$, 147.1, 132.2, 128.9, 123.1, 119.1, 109.9, 74.4, 31.6, 30.9, 30.2, 25.7, 22.6, 14.1 ppm. HRESI-MS (pos.) 724.4472 calc. for $\left[\mathrm{C}_{48} \mathrm{H}_{57} \mathrm{~N}_{3} \mathrm{O}_{3} \cdot \mathrm{H}\right]^{+}=724.4478 \mathrm{Da}$.

\section{Tris(hexyloxy)benzene tris-ester 9}

To a solution of 5 ( $0.496 \mathrm{~g}, 0.734 \mathrm{mmol}, 1$ equiv) in THF $(87 \mathrm{~mL}$ ) was added 4-methoxycarbonylphenylboronic acid (0.531 g, 2.97 mmol, 4.0 equiv) and $\mathrm{K}_{2} \mathrm{CO}_{3(\mathrm{aq})}(2.0 \mathrm{M}$, $11 \mathrm{~mL}$ ) to produce a pale yellow solution. The solution was deoxygenated with bubbling $\mathrm{N}_{2}$ for 20 minutes and then $\mathrm{Pd}\left(\mathrm{PPh}_{3}\right)_{4}(0.131 \mathrm{~g}, 0.109 \mathrm{mmol}, 0.149$ equiv) was added. The solution was heated at $75^{\circ} \mathrm{C}$ for 48 hours under $\mathrm{N}_{2}$, during which time it turned black. The mixture was cooled to room temperature and water $(100 \mathrm{~mL})$ was added. The solution was extracted ethyl acetate $(3 \times 75 \mathrm{~mL})$, and the combined organic layers were washed with water $(75 \mathrm{~mL})$ and brine $(75 \mathrm{~mL})$, then dried $\left(\mathrm{MgSO}_{4}\right)$. The solution was concentrated under vacuum to give the crude product as a black oily solid, which was purified by column chromatography (gradient: $5-10 \%$ EtOAc in pet. spirits) to 
give the product as colourless oil. Yield $0.156 \mathrm{~g}(0.189$ mmol, $26 \%$ ).

${ }^{1} \mathrm{H}-\mathrm{NMR}\left(400 \mathrm{NMR}, \mathrm{CDCl}_{3}\right): 7.91(\mathrm{~d}, J=8.2 \mathrm{~Hz}, 6 \mathrm{H})$, $7.21(\mathrm{~d}, J=8.2 \mathrm{~Hz}, 6 \mathrm{H}), 4.06(\mathrm{~s}, 6 \mathrm{H}), 3.89(\mathrm{~s}, 9 \mathrm{H}), 3.51$ (t, $J=6.6 \mathrm{~Hz}, 6 \mathrm{H}), 1.54 \mathrm{dt}, J=6.6,6.6 \mathrm{~Hz}, 6 \mathrm{H}), 1.08-1.25(\mathrm{~m}$, $18 \mathrm{H}), 0.80(\mathrm{t}, J=7.0 \mathrm{~Hz}, 9 \mathrm{H}) .{ }^{13} \mathrm{C}$ NMR $\left(101 \mathrm{MHz}, \mathrm{CDCl}_{3}\right)$ : 167.3, 156.8, 147.3, 129.7, 128.2, 127.9, 123.5, 74.2, 52.1, $31.7,30.9,30.2,25.7,22.7,14.1$ ppm. HRESI-MS (pos.) 823.4792, calc. for $\left[\mathrm{C}_{51} \mathrm{H}_{66} \mathrm{O}_{9} \cdot \mathrm{H}\right]^{+}=823.4785 \mathrm{Da}$.

\section{Tris(hexyloxy)benzene tris-carboxylic acid $7^{3 \mathrm{H}}$}

$\mathrm{NaOH}_{(\mathrm{aq})}(2.0 \mathrm{M}, 2 \mathrm{~mL})$ was added to a solution of 9 $(0.110 \mathrm{~g}, 0.133 \mathrm{mmol})$ in methanol $(14 \mathrm{~mL})$ and THF $(15 \mathrm{~mL})$. The yellow solution was then refluxed for 24 hours under $\mathrm{N}_{2}$, during which time it turned a reddish colour. After cooling to room temperature the solution was concentrated under vacuum until the volume of solvent was reduced by approximately half. Then conc. $\mathrm{HCl}_{(\mathrm{aq})}$ was added dropwise until no more solid formed $(\sim 1 \mathrm{~mL})$. The resulting white powder was isolated via filtration and washed with water $(3 \times 10 \mathrm{~mL})$ and diethyl ether $(1 \times$ $10 \mathrm{~mL}$ ) and dried under vacuum to give $7^{3 \mathrm{H}}$. Yield $0.082 \mathrm{~g}$ (0.105 mmol, $81 \%)$.

${ }^{1} \mathrm{H}-\mathrm{NMR}\left(400 \mathrm{MHz}, \mathrm{d}_{6}\right.$-DMSO): 12.70 (br. s., 3H), 7.82 (d, $J=8.2 \mathrm{~Hz}, 6 \mathrm{H}), 7.20(\mathrm{~d}, J=8.2 \mathrm{~Hz}, 6 \mathrm{H}),, 4.03(\mathrm{~s}, 6 \mathrm{H})$, $3.54(\mathrm{t}, J=6.7 \mathrm{~Hz}, 6 \mathrm{H}), 1.47$ (dt, $J=6.7,6.7 \mathrm{~Hz}, 6 \mathrm{H}), 1.04$ $1.17(\mathrm{~m}, 18 \mathrm{H}), 0.74(\mathrm{t}, J=6.9 \mathrm{~Hz}, 9 \mathrm{H}) .{ }^{13} \mathrm{C}$ NMR $\left(\mathrm{d}^{6}{ }_{-}\right.$ DMSO): 167.3, 156.3, 146.6, 129.3, 128.3, 127.9, 123.0, 73.5, 30.9, 30.1, 29.4, 24.9, 22.0, 13.8 ppm. HRESI-MS (neg.) 779.4156 , calc. for $\left[\mathrm{C}_{48} \mathrm{H}_{68} \mathrm{O}_{9}\right]^{-}=779.4159 \mathrm{Da}$.

\section{Tris(hexyloxy)benzene tris-carboxylate $\mathrm{TBA}_{3} \cdot 7$}

The tricarboxylic acid $7^{3 \mathrm{H}}(0.060 \mathrm{~g}, 0.077 \mathrm{mmol}, 1$ equiv $)$ was suspended in ethanol $(5 \mathrm{~mL})$ and a solution of TBA.OH in methanol ( $1.0 \mathrm{M}, 0.23 \mathrm{~mL}, 0.23 \mathrm{mmol}, 3.0$ equiv) was added causing the solid to dissolve. The resultant solution was stirred at room temperature for 1 hour under $\mathrm{N}_{2}$. The solution was then concentrated under vacuum to give the product as a pale yellow oil. Yield $0.116 \mathrm{~g}(0.077 \mathrm{mmol}$, $100 \%)$.

${ }^{1} \mathrm{H}-\mathrm{NMR}\left(400 \mathrm{NMR} \mathrm{CDCl}_{3}\right): 7.84(\mathrm{~d}, J=7.9 \mathrm{~Hz}, 6 \mathrm{H})$, $7.05(\mathrm{~d}, J=7.9 \mathrm{~Hz}, 6 \mathrm{H}), 3.93(\mathrm{~s}, 6 \mathrm{H}), 3.56(\mathrm{t}, J=6.4 \mathrm{~Hz}$, $6 \mathrm{H}), 3.13-3.24(\mathrm{~m}, 24 \mathrm{H}), 1.53-1.58(\mathrm{~m}, 6 \mathrm{H}), 1.43-1.45(\mathrm{~m}$, $24 \mathrm{H}), 1.20-1.28(\mathrm{~m}, 42 \mathrm{H}) 0.79-0.84(\mathrm{~m}, 45 \mathrm{H}) \mathrm{ppm} .{ }^{13} \mathrm{C}-$ NMR $\left(101 \mathrm{MHz} \mathrm{CDCl}_{3}\right): 171.9,156.5,142.9,137.3,129.4$, 127.3, 124.2, 100.2, 74.1, 58.7, 31.9, 30.5, 25.8, 24.1, 22.7, 19.8, 14.2, 13.8 ppm. HRESI-MS (neg.) 509.8429, calc. for $\left[\mathrm{C}_{64} \mathrm{H}_{93} \mathrm{O}_{9} \mathrm{~N} \text {, i.e. TBA.7 }\right]^{2-}=509.8420 \mathrm{Da}$.

\section{X-ray crystallography}

Data were collected on the $M X 2$ beamline ${ }^{42}$ at the Australian Synchrotron at $100 \mathrm{~K}$, Raw frame data (including data reduction, interframe scaling and unit cell refinement) were processed using XDS. ${ }^{43}$ The structure was solved using Superflip, ${ }^{44}$ and refined using full-matrix least-squares on $F^{2}$ within the Crystals suite. ${ }^{45}$ All non- hydrogen atoms were refined with anisotropic displacement parameters. A thermal ellipsoid plot and crystallographic data table are included in the Supporting Information and the data in CIF format have been uploaded to the Cambridge Structural Database (CCDC: 2080276).

Despite numerous attempts to grow high quality crystals, only small and weakly-diffracting crystals could be obtained. It was not possible to resolve the hexyloxy chains, and so these were represented with an oxygen and carbon atom with the remaining electron density included in the model using PLATON-SQUEEZE. ${ }^{38}$ It was felt that this was a more honest representation of the structure than "constructing" hexyl chains at arbitrary locations using copious amounts of crystallographic restraints. While the resulting structural model is of relatively low quality, it unambiguously allows the determination of the structural connectivity.

\section{Calculations}

Gas phase energy minimizations of $\mathbf{1}_{2} \cdot \mathbf{T P}_{\mathbf{3}}$ and $\mathbf{2}_{\mathbf{2}} \cdot \mathrm{IP}_{\mathbf{3}}$ were conducted using PM6 parameters ${ }^{33}$ within Spartan. ${ }^{46}$ The gas phase energy minimization of $\mathbf{8}_{\mathbf{3}} \cdot \mathbf{7 2}$ is described in the Supporting Information. Atomic coordinates for all three structures are provided in the Supporting Information.

\section{Acknowledgements}

We thank Tom Anglim Lagones and Esther van Praag for preliminary experiments on related systems, Prof. Christian Doonan for providing an initial sample of $\mathbf{3}$, and Chris Blake and Dr Daniel Preston for assistance with DOSY NMR spectroscopy. We thank the Australian Research Council (Australian Government RTP Scholarship to EMF and DE170100200 to NGW) and the ANU Summer Scholars Program (SEW) for funding. Parts of this work were conducted using the MX2 Beamline of the Australian Synchrotron. ${ }^{42}$

\section{Conflict of interest statement}

The authors declare no conflicts of interest.

\section{References}

1. M. Yoshizawa, J. K. Klosterman and M. Fujita, Angew. Chem., Int. Ed., 2009, 48, 3418-3438.

2. T. Hasell and A. I. Cooper, Nat. Rev. Mat., 2016, 1, 16053.

3. A. Galan and P. Ballester, Chem. Soc. Rev., 2016, 45, 1720-1737.

4. V. Mouarrawis, R. Plessius, J. I. van der Vlugt and J. N. H. Reek, Front. Chem., 2018, 6, 623.

5. Y. Xue, X. Hang, J. Ding, B. Li, R. Zhu, H. Pang and Q. Xu, Coord. Chem. Rev., 2020, 430, 213656.

6. L. R. MacGillivray and J. L. Atwood, Nature, 1997, 389, 469-472.

7. T. Heinz, D. M. Rudkevich and J. Rebek, Nature, 1998, 394, 764-766. 
8.

Y. Liu, C. Hu, A. Comotti and M. D. Ward, Science, 2011, 333, 436-440.

9. L. Adriaenssens and P. Ballester, Chem. Soc. Rev., 2013, 42, 3261-3277.

10. O. Dumele, N. Trapp and F. Diederich, Angew. Chem., Int. Ed., 2015, 54, 12339-12344.

11. L. Turunen, U. Warzok, R. Puttreddy, N. K. Beyeh, C. A. Schalley and K. Rissanen, Angew. Chem., Int. Ed., 2016, 55, 14033-14036.

12. L.-J. Riwar, N. Trapp, K. Root, R. Zenobi and F. Diederich, Angew. Chem., Int. Ed., 2018, 57, 1725917264.

13. Y.-J. Zhu, Y. Gao, M.-M. Tang, J. Rebek and Y. Yu, Chem. Commun., 2021, 57, 1543-1549.

14. F. Corbellini, R. Fiammengo, P. Timmerman, M. Crego-Calama, K. Versluis, A. J. R. Heck, I. Luyten and D. N. Reinhoudt, J. Am. Chem. Soc., 2002, 124, 6569-6575.

15. F. Corbellini, L. Di Costanzo, M. Crego-Calama, S. Geremia and D. N. Reinhoudt, J. Am. Chem. Soc., 2003, 125, 9946-9947.

16. B. Kuberski and A. Szumna, Chem. Commun., 2009, 1959-1961.

17. H. Katagiri, Y. Tanaka, Y. Furusho and E. Yashima, Angew. Chem., Int. Ed., 2007, 46, 2435-2439.

18. M. Kohlhaas, M. Zähres, C. Mayer, M. Engeser, C. Merten and J. Niemeyer, Chem. Commun., 2019, 55 3298-3301.

19. Y. Tanaka, H. Katagiri, Y. Furusho and E. Yashima, Angew. Chem., Int. Ed., 2005, 44, 3867-3870.

20. M. Ikeda, Y. Tanaka, T. Hasegawa, Y. Furusho and E. Yashima, J. Am. Chem. Soc., 2006, 128, 6806-6807.

21. Y. Nakatani, Y. Furusho and E. Yashima, Angew. Chem., Int. Ed., 2010, 49, 5463-5467.

22. M. W. Hosseini, R. Ruppert, P. Schaeffer, A. De Cian, N. Kyritsakas and J. Fischer, J. Chem. Soc., Chem. Commun., 1994, 2135-2136.

23. T. Kusukawa, K. Matsumoto, H. Nakamura, W. lizuka, K. Toyama and S. Takeshita, Org. Biomol. Chem., 2013, 11, 3692-3698.

24. N. G. White, Dalton Trans., 2019, 48, 7062-7068.

25. J. Bernstein, R. E. Davis, L. Shimoni and N.-L. Chang, Angew. Chem., Int. Ed., 1995, 34, 1555-1573.

26. N. Kamali, M. Aljohani, P. McArdle and A. Erxleben, Cryst. Growth Des., 2015, 15, 3905-3916.

27. L. Pop, N. D. Hadade, A. van der Lee, M. Barboiu, I. Grosu and Y.-M. Legrand, Cryst. Growth Des., 2016. 16, 3271-3278.

28. M. Thomas, T. Anglim Lagones, M. Judd, M. Morshedi, M. L. O'Mara and N. G. White, Chem. Asian J., 2017, 12, 1587-1597.

29. M. Morshedi, M. Thomas, A. Tarzia, C. J. Doonan and N. G. White, Chem. Sci., 2017, 8, 3019-3025.

30. S. A. Boer, M. Morshedi, A. Tarzia, C. J. Doonan and N. G. White, Chem. Eur. J., 2019, 25, 10006-10012.

31. J. Nicks, S. A. Boer, N. G. White and J. A. Foster, Chem. Sci., 2021, 12, 3322-3327.

32. For a review of the supramolecular chemistry of these species in an anion recognition context, see: S. M. Butler and K. A. Jolliffe, Org. Biomol. Chem. 2020, 18 , 8236-8254.

33. J. J. P. Stewart, J. Mol. Model., 2007, 13, 1173-1213.

34. A. Avellaneda, P. Valente, A. Burgun, J. D. Evans, A. W. Markwell-Heys, D. Rankine, D. J. Nielsen, M. R. Hill, C. J. Sumby and C. J. Doonan, Angew. Chem., Int. Ed., 2013, 52, 3746-3749.
É. M. Foyle and N. G. White, CrystEngComm, 2020 , 22, 2526-2536.

S. Kotha, K. Mandal, K. K. Arora and V. R. Pedireddi, Adv. Synth. Catal., 2005, 347, 1215-1218.

We note that there are considerable difficulties with determining solvodynamic radii for non-spherical species. As well as using the Stokes-Einstein equation, we have calculated the diffusion values for the supramolecular assemblies and for the $\mathbf{1}^{3+}$ or $7^{3-}$ alone relative to $\mathrm{TBA}^{+}$or $\mathrm{BPh}_{4}^{-}$as internal references. In each case, the increase in size calculated using this method is the same within $10 \%$ as the value calculated using the Stokes-Einstein equation (see Supporting Information for more details).

38. A. L. Spek, Acta Crystallogr., 2015, C71, 9-18.

39. X. Wang and F. Hof, Beilstein J. Org. Chem., 2012, 8, 1-10.

40. A. J. Lowe and F. M. Pfeffer, Chem. Commun., 2008, 1871-1873.

41. H. E. Gottlieb, V. Kotlyar and A. Nudelman, J. Org. Chem., 1997, 62, 7512-7515.

42. D. Aragao, J. Aishima, H. Cherukuvada, R. Clarken, M. Clift, N. P. Cowieson, D. J. Ericsson, C. L. Gee, S. Macedo, N. Mudie, S. Panjikar, J. R. Price, A. RiboldiTunnicliffe, R. Rostan, R. Williamson and T. T. Caradoc-Davies, J. Synchrotron Radiat., 2018, 25, 885-891.

43. W. Kabsch, J. Appl. Crystallogr., 1993, 26, 795-800.

44. L. Palatinus and G. Chapuis, J. Appl. Crystallogr., 2007, 40, 786-790.

45. P. W. Betteridge, J. R. Carruthers, R. I. Cooper, K. Prout and D. J. Watkin, J. Appl. Crystallogr., 2003, 36, 1487.

46. Spartan 18, Wavefunction Inc. 